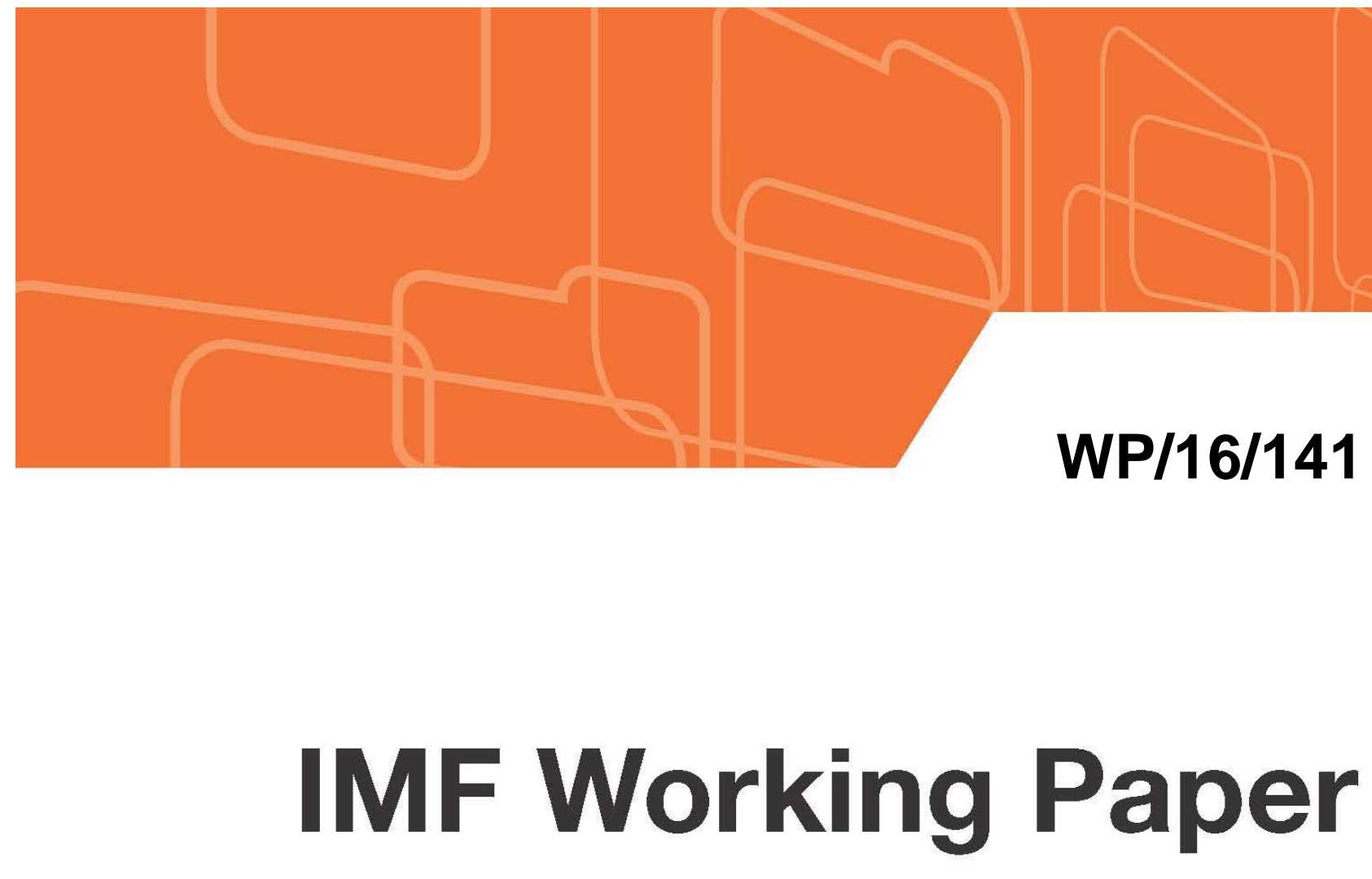

\title{
The Role of Fiscal Transfers in Smoothing Regional Shocks: Evidence from Existing Federations
}

by Tigran Poghosyan, Abdelhak Senhadji, and Carlo Cottarelli 


\title{
IMF Working Paper
}

Fiscal Affairs Department

\section{The Role of Fiscal Transfers in Smoothing Regional Shocks: Evidence from Existing Federations}

\section{Prepared by Tigran Poghosyan, Abdelhak Senhadji, and Carlo Cottarelli ${ }^{1}$}

Authorized for distribution by Abdelhak Senhadji

June 2016

\begin{abstract}
IMF Working Papers describe research in progress by the author(s) and are published to elicit comments and to encourage debate. The views expressed in IMF Working Papers are those of the author(s) and do not necessarily represent the views of the IMF, its Executive Board, or IMF management.
\end{abstract}

\begin{abstract}
We assess the extent to which fiscal transfers smooth regional shocks in three large federations: the U.S., Canada, and Australia. We find that fiscal transfers offset 4-11 percent of idiosyncratic shocks (risk-sharing) and 13-24 percent of permanent shocks (redistribution). This fiscal insurance largely operates through automatic stabilizers embedded in a central budget primarily through federal taxes and transfers to individuals, rather than transfers from the central government to state budgets. These results have implications for the design of fiscal risk-sharing mechanisms in the euro area.
\end{abstract}

JEL Classification Numbers: E62; H77

Keywords: fiscal federalism, risk-sharing, redistribution

Author's E-Mail Address: tpoghosyan@imf.org, asenhadji@imf.org,ccottarelli@imf.org.

\footnotetext{
${ }^{1}$ An earlier version of this paper appeared in: Poghosyan, T., A. Senhadji, and C. Cottarelli, 2015, "The Role of Fiscal Transfers in Smoothing Regional Shocks," in: Cottarelli, C., and M. Guerguil (eds.), Designing a European Fiscal Union: Lessons from the Experience of Fiscal Federations (Oxford, UK: Routledge Press). We would like to thank Celine Allard, Tamim Bayoumi, Helge Berger, John Bluedorn, Jorg Decressin, Davide Furceri, Emine Hanedar, Petya Koeva Brooks, and Todd Mattina for useful comments and suggestions. Malin Hu has provided excellent assistance. The usual disclaimer applies.
} 
I. Introduction . 4

II. Does a Central Budget Enhance Insurance Against Macroeconomic Shocks? Review of Main Theoretical Arguments.

III. Redistribution and Risk-Sharing in Existing Federations: Empirical Approaches and Evidence from Previous Studies

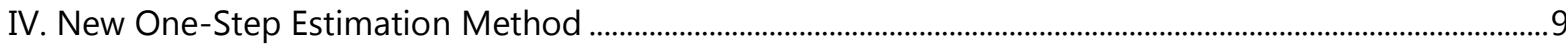

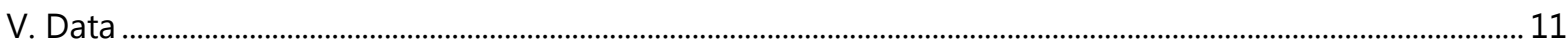

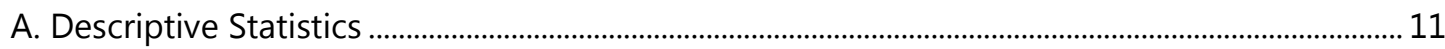

B. Preliminary Evidence on Redistribution ................................................................................................ 12

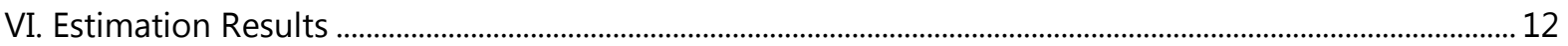

A. Bayoumi and Masson (1995): Two-Step Approach ......................................................................... 12

B. Pooled Mean Group Estimator: One-Step Approach...................................................................... 13

VII. The Role of Individual Components of Net Fiscal Transfers in Cushioning the Impact of Shocks ... 14

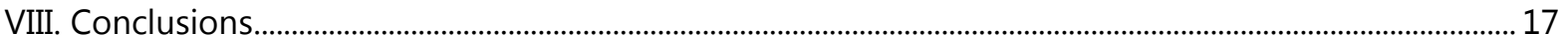

References...1.

Annexes

1. Empirical approaches used in existing literature to quantify the impact of fiscal transfers ................... 21

2. Data description and sources .......................................................................................................................... 24

Tables

1. Empirical Estimates of Redistribution and Risk-sharing from Previous Studies......................................... 25

2. Estimation Results Based on Bayoumi and Masson (1995) Two-step Approach...................................... 26

3. Estimation Results Based on the Pooled Mean Group (PMG) Estimator ..................................................... 27

4. Estimation Results Using an Alternative Specification to Assess the Impact of Stabilization and

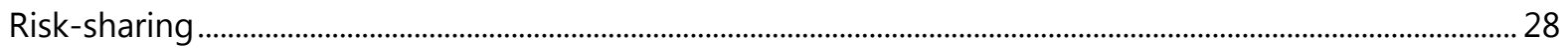

Figures

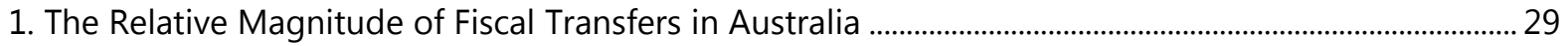

2. The Relative Magnitude of Fiscal Transfers in Canada .................................................................................... 30

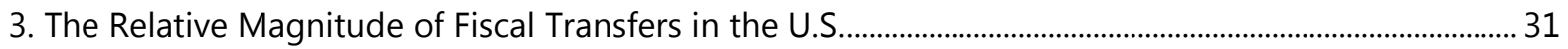

4. Redistribution through Net Fiscal Transfers in the U.S. (1998-2010) ....................................................... 32

5. Redistribution through Net Fiscal Transfers in Canada (1992-2009)............................................................ 33

6. Redistribution through Net Fiscal Transfers in Australia (1998-2010) .......................................................... 34 


\section{INTRODUCTION}

This chapter analyses the role of net fiscal transfers in mitigating the impact of regional shocks on subnational public finances in federations. As discussed in Chapter 1 , fiscal transfers play different roles, including closing vertical imbalances, achieving redistribution goals, and insuring states or provinces against macroeconomic shocks. The latter role in turn could be subdivided into insurance against idiosyncratic macroeconomic shocks hitting individual states (risk-sharing) and insurance against common shocks hitting all states simultaneously (stabilization). This chapter focuses on the extent of risk sharing - an issue that has figured front and center in the discussion regarding euro area institutions in recent years-and, relatedly, whether a federal system with a central budget—or equivalent risk-sharing mechanisms—would achieve better insurance against macroeconomic shocks than a system without it.

Disentangling the respective roles of redistribution, stabilization and risk-sharing is complicated as in most federations fiscal transfers play them simultaneously. ${ }^{2}$ Ideally, measuring risk sharing would require conducting a counterfactual analysis and comparing the magnitudes of insurance in existing federations before and after a central budget had been established. In practice, conducting such analysis is not possible given the difficulty of finding data on federations before the establishment of a central budget (i.e. the counterfactual), as almost all existing federations have been functioning with centralized fiscal systems for decades now. Therefore, we follow an alternative route. First, drawing on the literature, we discuss the relative effectiveness of centralized versus decentralized fiscal systems in offsetting the impact of macroeconomic shocks. Second, we assess empirically the importance of risk-sharing in three large fiscal federations (Australia, Canada, and the U.S.), and the mechanisms through which this risk-sharing occurs. ${ }^{3}$ This chapter also offers some methodological refinements in the estimation of risk-sharing and redistribution motives of fiscal transfers. It starts with the standard two-step approach that has been used in the literature - where redistribution and risk-sharing motives are estimated separately —and proposes a new, more efficient one-step approach. It also proposes an alternative approach which allows one to assess separately the extent to which individual components of net fiscal transfers contribute to risk-sharing (and redistribution).

The reminder of this chapter is structured as follows. Section II summarizes the theoretical arguments on whether a central budget in federations could enhance insurance against

\footnotetext{
${ }^{2}$ Nevertheless, it is important to make a clear distinction between these roles, as terminology used in previous studies lacks consistency and contributes to some confusion (for instance, Bayoumi and Masson (1995) refer to the risk-sharing objective as "stabilization").

${ }^{3}$ Restriction of the sample to these three federations is driven by data availability. For the purpose of this chapter, and unless otherwise specified, the term "net fiscal transfers" (or simply "fiscal transfers") refers to net fiscal flows between central and sub-national governments. Specifically, net fiscal transfers are defined as the difference between gross transfers from the center to sub-national governments (either to the sub-national budget or to residents) and taxes paid by sub-national government residents to the center. The term "subnational" refers to state/provincial governments. We do not consider lower level government such as local regions and municipalities.
} 
macroeconomic shocks. Section III reviews existing empirical approaches for measuring the impact of fiscal transfers on redistribution and insurance, and summarizes the evidence from the previous literature. Section IV introduces an efficient one-step empirical methodology to estimate fiscal risk-sharing and redistribution. Section $V$ describes the data and provides summary statistics. Section VI presents estimation results from two empirical methodologies: the standard two-step approach used in previous studies and our new more efficient methodology. Section VII introduces a third empirical approach which allows us to assess separately the role of individual gross components of net fiscal transfers in dampening the impact of shocks through fiscal transfers. The last section concludes.

\section{Does a Central Budget Enhance Insurance Against Macroeconomic Shocks? Review of MAIN THEORETiCAL ARgumentS}

Members of a fiscal federation benefit from insurance against income shocks in the same way that individuals do - it enables them to buffer their consumption path in the face of such shocks. The logic of consumption-smoothing was famously articulated by Friedman (1957) in his treatise on the permanent income hypothesis. He demonstrated how consumers with access to credit markets would save and borrow to make their consumption path smoother than their income path.

In addition to saving and borrowing in credit markets, risk pooling across members of a federation can also help smooth the consumption path at the state level-states that do better than usual at a certain period in time help insure states that are doing worse than usual. Over time, the benefits of this arrangement are expected to be shared across members of a federation, as no state should perform consistently better or worse than the average one.

Various studies discuss how fiscal centralization can, in theory, enhance the extent of insurance against macroeconomic shocks (see for more detailed discussions the surveys in Beetsma and Debrun, 2004 and Beetsma and Giuliodori, 2010):

- Risk-sharing (interregional insurance). A centralized fiscal system allows, states to pool risks emanating from idiosyncratic shocks. This interregional insurance works on top of the stabilization function (or intertemporal insurance). Some commentators justify the importance of risk-sharing in federations with the fact that in the absence of state-specific exchange rates, shocks hitting individual states and provinces cannot be cushioned through changes in terms of trade given price stickiness. In addition, households will have limited capacity to smooth regional shocks if markets for production inputs (labor and capital) are not mobile enough or if private credit markets do not function properly. ${ }^{4}$

\footnotetext{
${ }^{4}$ In addition to the direct effect on risk-sharing, fiscal centralization can also contribute to enhancing risk-sharing through private markets. For instance, unified regulation and deposit insurance may reduce information asymmetries and encourage more diversified market portfolio holdings, thereby leading to greater risk sharing via markets, an aspect that is not discussed in this chapter.
} 
- Scale economies. Another argument in favor of centralizing countercyclical fiscal policies is related to scale economies benefiting central governments in performing their stabilization function. An important factor here is the ability of the central government to borrow at better terms from markets compared to individual states. This is vividly illustrated in the case of the U.S., where states pay a risk-premium over Treasury bond yields to borrow from markets.

- Fiscal spillovers and fiscal policy coordination. Some studies argue that fiscal stabilization is of a "public good" nature. They point out that highly integrated neighboring states are likely to benefit from stabilization measures carried out by one of them, since the impact of these measures is likely to leak out to other states through interstate trade spillovers. As a result, a "free-riding" problem emerges making decentralized policies excessively passive. In particular, uncoordinated state-specific fiscal policies may not be as effective as coordinated policies run at the central level that internalize these spillover effects (Hamada, 1985). Some have underscored the efficacy of a centralized fiscal policy in the particular case where monetary policy reaches its lower bound.

- Ricardian equivalence. In the presence of (even partly) Ricardian households, the stabilization function of state fiscal policies in a fully decentralized fiscal system can be hampered by the decision of households to increase savings in periods of fiscal expansion in anticipation that higher deficits will need to be financed through higher taxes in a later period. In other words, fiscal multipliers in a fully decentralized system with Ricardian households will be very weak. By contrast, Ricardian effects tend to have a smaller impact on fiscal multipliers in centralized fiscal systems, since households in states running deficits may expect that the financing of those deficits will be shared with households living in other states. For instance, Bayoumi and Masson (1998) find that in Canada a non-liability creating stabilization would be two to three times more effective than decentralized stabilization financed through the increase in the local public debt.

However, there are also arguments against the centralization of fiscal policy in the context of stabilization and risk-sharing:

- Design issues. The arguments above for centralization of fiscal policy ignore issues related to the design of an efficient tax and transfer system necessary to achieve a well-coordinated stabilization policy and efficient risk-sharing. In particular, it is difficult to design a federal fiscal system that would exclusively minimize the variability of regional income without leading to a systematic redistribution of income from rich to poor regions. Indeed, empirical evidence suggests that the former consistently pay higher federal taxes and receive lower federal transfers on average (Goodhart and Smith, 1993).

- Moral hazard issues. Implicit bailout guarantees offered by the centralized fiscal arrangement may decrease incentives for good policies. This classic moral hazard problem could worsen the fiscal position of states and increase their vulnerability to macroeconomic shocks. The moral hazard argument has been put forward by the Eurobond skeptics arguing that Eurobonds would weaken market discipline and lead individual governments to postpone long-overdue reforms (Chapter 3 discusses moral hazard issues in federations in greater detail). It could also be used for other types of insurance schemes, such as the one 
that is the focus of in this paper, whereby the central government provides member states transfers to offset the impact of shocks.

Overall, given these contrasting theoretical arguments, the issue is how much, in practice, central budgets help cushion the impact of regional shocks.

\section{Redistribution AND Risk-Sharing in Existing Federations: Empirical Approaches AND EVIDENCE FROM PREVIOUS STUdiES}

As mentioned above, fiscal transfers in federations have two important effects on regional incomes: (i) redistribution, or permanent transfer of funds from richer to poorer regions to help convergence of regional living standards to the national average, and (ii) insurance against macroeconomic shocks, or temporary transfer of funds to smooth out the impact of idiosyncratic regional (risk-sharing) and common (stabilization) shocks. ${ }^{5}$

More specifically, insurance measures the extent to which fiscal transfers offset regional disposable incomes from temporary shocks to regional outputs. For instance, a level of insurance of 10 percent implies that the disposable income of a given region would fall by 90 cents in response to a temporary decline in its output by $\$ 1$. This temporary decline in output could be either relative to the national average output (risk-sharing) or a simultaneous decline in output across all regions (stabilization). Similarly, the magnitude of the redistribution effect measures the extent to which fiscal transfers flow from the relatively rich regions to the poor ones. For example, a redistribution effect of 20 percent would imply that a region with a $\$ 1$ permanently lower output relative to the national average (as a result of a permanent shock) would have a disposable income that is only 80 cents below the national average, with the rest 20 cents being covered by the permanent transfer of funds from richer regions.

The literature uses three empirical approaches to quantify the effect of fiscal transfers in the U.S. and other federations (Annex 1 provides a technical review of these approaches and Table 1 summarizes the results):

- The first approach, pioneered by Sachs and Sala-i-Martin (1992), assesses the overall impact of fiscal transfers on redistribution and risk-sharing, without distinguishing between the two. Using data on 9 U.S. regions for the period 1970-80, the authors estimate a combined cushioning effect of net fiscal transfers in the range of 33-40 percent of the initial shock and conclude that the U.S. federal fiscal system substantially smoothes regional income shocks. Masson and Taylor (1993) adopt the same methodology to study fiscal transfers in Canada during 1965-1988. They find that the effect of net fiscal transfers is only 13 percent; and that

\footnotetext{
${ }^{5}$ We disregard here the existence of transfers that take place purely to offset structural vertical imbalances that are the same across regions, as the focus here is on transfers that are different across regions, or that change over the cycle (see Chapter 1). We also do not analyze crisis episodes, when fiscal transfers from central government are used to bail out states under financial stress. A detailed discussion of sub-national government crises is presented in Chapter 6.
} 
federal taxes play a more important role in cushioning the impact of regional shocks (4 to 22 percent, averaging 12 percent when weighted by population) compared to gross fiscal transfers (-26 to 10 percent, averaging close to zero when weighted by population). Using Swedish data for the period 1983-2001, Andersson (2004) concludes that net fiscal transfers absorb between 7-22 percent of an initial shock to personal income. Similar to Masson and Taylor, her results indicate that taxes play a more important role than gross fiscal transfers.

- The second approach was proposed by Von Hagen (1992). As mentioned above, the issue with Sachs and Sala-i-Martin's approach is that it does not distinguish between redistribution and insurance motives. Von Hagen uses an alternative specification that disentangles risksharing from redistribution. Because this specification relies on two separate regressionsone for risk-sharing and another for redistribution-this approach will be referred to as the two-step approach. Using data on 48 states of the U.S. during 1981-86, Von Hagen obtains a much smaller estimate of insurance against regional shocks, amounting to 10 percent. However, he finds a large redistribution effect of 47 percent. Von Hagen's two-step methodology was adopted by Goodhart and Smith (1993) to study the role of fiscal transfers in a wider set of countries, including the U.S. (1982-86), Canada (1965-88), and the United Kingdom (1983-87). The results on risk-sharing for the U.S. (11 percent) are comparable to those in Von Hagen; however they find a smaller redistribution effect (13 percent). ${ }^{6}$ In Canada and the United Kingdom, the impact of fiscal transfers on risk-sharing (17 and 21 percent, respectively) and redistribution (15 and 21 percent, respectively) was found to be relatively larger compared to the respective estimates for the U.S.

- The third approach was outlined in Bayoumi and Masson (1995). Similar to Von Hagen's, this is a two-step approach, but unlike Von Hagen's, it does not separately identify the effects of federal taxes and of gross fiscal transfers. Using data on states in the U.S. and Canadian provinces during 1969-1986, Bayoumi and Masson find a stronger redistributive effect of net fiscal transfers in Canada (39 percent) relative to the U.S. (22 percent). By contrast, the risksharing effect of net fiscal transfers is found to be larger in the U.S. (31 percent) compared to Canada (17 percent). Using Bayoumi and Masson's approach and focusing on shocks to regional personal income, rather than regional GDP, Melitz and Zumer (2002) find that risksharing between regions in France or in the United Kingdom is similar in magnitude to that in the U.S. (20 percent). Redistribution, however, is larger in France (38 percent) and in the United Kingdom (26 percent) than in the U.S. and Canada (16 percent). Obstfeld and Peri (1998) use a dynamic version of Bayoumi and Masson's two-step approach by specifying a bivariate vector autoregression (VAR) model on demeaned regional incomes to analyze the impact of net fiscal transfers in the U.S., Canada, and Italy. They find a first year risk-sharing effect of 10-13 percent for the U.S. and Canada, comparable to previous estimates, but the magnitude is much smaller for Italy (3 percent). The long-run redistribution effect is the strongest in Canada (53 percent), followed by the U.S. (19 percent) and Italy (8 percent).

\footnotetext{
${ }^{6}$ The smaller redistribution effect may be due to differences in state coverage: Goodhart and Smith use data on 44 states only, excluding five oil-exporting states and Washington D.C. from the sample.
} 
Decressin (2002) repeats this exercise for the case of Italy using the period 1970-95 and finds much larger risk-sharing (10-15 percent) and redistribution (25-35 percent) effects.

Overall, the evidence from the reviewed studies suggests that risk-sharing and redistribution estimates vary widely across countries, sample periods, and estimation methods (Table 1). For instance, using the same methodology, Sachs and Sala-i-Martin, Masson and Taylor, and Andersson find substantially different estimates for the U.S., Canada, and Sweden, respectively. Nevertheless, a common pattern emerges: the redistributive motive is generally stronger than risk-sharing. For instance, in the U.S. the average estimate of risk-sharing (14 percent) is about half of the average estimate of redistribution (23 percent). However, these studies use relatively old data sets and an arbitrary two-step procedure. In addition, they do not separate the impact of automatic transfers (arising from the operation of centralized automatic stabilizers) from that of discretionary transfers. The following sections attempt to address these issues using more recent data on three federations and three empirical methodologies-the conventional two-step approach, a new one-step procedure, and separate estimates for different types of transfers. ${ }^{7}$

\section{New One-Step Estimation Method}

As discussed in the previous section, the existing literature uses a two-step approach for measuring the relative magnitudes of fiscal risk-sharing and redistribution. The redistribution effect is typically measured using a cross-sectional regression on average levels of regional variables (equation A-6 in Annex 1), while the risk-sharing effect is measured using panel data regressions on changes of regional variables (equation A-7). To ensure the robustness of results, we complement the two-step methodology used in previous studies with a new one that assesses the effect of redistribution and risk-sharing in one step. While this methodology mirrors the two-step approach (with a one-to-one mapping of the coefficient estimates as shown below), it is more efficient because it combines the high and low frequency information in the data. In particular, it accounts for the dynamic effects of fiscal transfers highlighted in Obstfeld and Peri (1998) by introducing a short-run adjustment of disposable income to its long-run equilibrium level.

More specifically, we apply the Pooled Mean Group (PMG) estimator of Pesaran et al. (1999), which is a panel data version of the error-correction model. The empirical specification takes the following form:

$$
\Delta\left(\frac{Y D_{i t}}{\overline{Y D}_{t}}\right)=\phi_{i}\left[\frac{Y D_{i t-1}}{\overline{Y D}_{t-1}}-\alpha-\beta \frac{Y_{i t-1}}{\bar{Y}_{t-1}}\right]+\delta_{i} \Delta\left(\frac{Y_{i t}}{\bar{Y}_{t}}\right)+\mu_{i}+\varepsilon_{i t}
$$

where $i$ and $t$ indices denote state and time, $Y_{i t}$ is the state-level real per capita GDP, YD it is the state-level real per capita disposable income after accounting for net fiscal transfers, $\overline{Y D}_{t}$ and $\bar{Y}_{t}$

\footnotetext{
${ }^{7}$ Since our objective is to distinguish between redistribution and insurance objectives, we do not consider the Sachs and Sala-i-Martin's approach.
} 
are national averages of respective variables in period $t_{1}^{8} \mu$ is the state-specific fixed effect, and $\varepsilon$ is an i.i.d. error term. The term in the squared bracket is the error-correction term measuring the extent of the deviation of the relative disposable income from its long-run equilibrium value itself (determined by the relative GDP).

The coefficients in specification (1) can be directly mapped to those in the two-step methodology of Bayoumi and Masson (1995) described in Annex 1 . The coefficient $\beta$ measures the redistribution effect of fiscal transfers (the equivalent of $\beta_{\text {redist }}$ in equation A.6 in Annex 1 ). More specifically, it indicates the long-run response of relative disposable income to a permanent change in relative GDP. ${ }^{9}$ Similarly, the coefficient $\delta$ measures the risk-sharing effect of fiscal transfers (the equivalent of $\beta$ risk-sharing in equation A.7 in Annex 1) given by the short-run response of changes in relative disposable income to transitory changes in relative GDP. The coefficient $\phi$ is the speed of adjustment of the relative disposable income to its long-run equilibrium value. The magnitude of this coefficient illustrates the dynamic effect of fiscal transfers: the larger is the absolute value of this coefficient, the faster is the adjustment of the relative disposable income to its long-run equilibrium value facilitated by the fiscal transfers. Finally, the specification includes state-specific fixed effects $\mu_{i}$ to capture unobserved heterogeneity of relative disposable income growth rates across states.

The one-step PMG specification has several advantages relative to the two-step approach employed in the previous literature. ${ }^{10}$ First, by combining the level and first difference regressions in one step, the PMG provides more efficient estimates of redistribution and risksharing. ${ }^{11}$ Second, the PMG estimator is more flexible and allows state-specific variation in shortrun coefficients $\left(\delta_{i}\right)$ measuring the degree of risk-sharing. The difference in the magnitude of fiscal risk-sharing across states reflects differences in the ability of individual states to insure against idiosyncratic shocks through private markets and reallocate production factors (labor and capital). In contrast, the PMG estimator pools long-run slope coefficients into a common coefficient $(\beta)$. This is consistent with the fact that redistribution formulas aiming to smooth longrun divergences of income across states are not expected to vary widely from state to state. Finally, the PMG specification can be tested against a more flexible Mean Group (MG) estimator that allows for both redistribution and risk-sharing coefficients to vary across states using the

\footnotetext{
8 Similar to Bayoumi and Masson (1995), the demeaning of variables allows controlling for stabilization effects, but does not allow identifying their impact.

${ }^{9}$ In technical terms, $\beta$ represents the cointegration coefficient linking the long-run relationship between relative disposable income and relative income at the regional level.

10 Bayoumi and Masson (1995) acknowledge that a one-step cointegration approach akin to ours would be preferable compared to their two-step approach (footnote 6, p. 257). However, the one-step approach did not yield satisfactory results for the long-run coefficients in their sample and therefore the authors decided to proceed with the two-step approach.

11 This is particularly relevant for the case of Canada, where the estimate of the redistribution effect is based on 10 observations only (i.e. the number of states in Canada) as the two-step method relies on a purely crosssectional regression where the number of observations is equal to the number of states.
} 
Hausman test. ${ }^{12}$ If the homogeneity assumption is rejected, the MG results could be used to analyze redistribution and risk-sharing.

\section{DATA}

We use data on three federations-Australia, Canada, and the U.S. For these federations, we collect information on total transfers from the federal government to state budgets (both earmarked transfers and block grants); these are based on pre-determined formulas that are not directly linked to the regional cyclical fluctuations. In addition, we obtain state-level information on gross federal transfers to individuals (including retirement, medical and income maintenance benefits, education and training assistance, unemployment insurance compensation) and taxes (including personal and corporate income taxes) that are largely driven by automatic stabilizers and are more closely related to regional cycles. ${ }^{13}$ For Australia and the U.S. the sample period spans from 1998 - 2010 (13 years), while for Canada from 1992 - 2009 (18 years). The length of the time series is comparable to those used in previous studies surveyed in Table 1 (averaging at 16 years). ${ }^{14}$ Annex 2 contains detailed information on data sources and sample periods.

\section{A. Descriptive Statistics}

Figures 1-3 show the magnitude of fiscal transfers in Australia, Canada, and the U.S. In all three countries fiscal transfers are sizeable. Federal tax revenues range between 15-20 percent of state GDP, while gross fiscal transfers range between 5-15 percent. The cyclical effect of gross fiscal transfers and taxes is clearly illustrated in the case of the U.S., where federal tax revenues have declined markedly and outlays increased significantly in 2009-2010. Federal taxes have also seen a sharp decline in the aftermath of the crisis in Canada and Australia while spending was somewhat less responsive than in the U.S. (except in Australia in 2009).

The figures also show that in all three countries, net transfers from the federal government have increased following the global financial crisis. This increase reflects a combination of automatic stabilizers and discretionary stimulus packages enacted to smooth out the impact of the crisis.

\footnotetext{
12 To illustrate the intuition, recall that the PMG estimator constraints the long-run slope coefficients to be equal across all states. This is in contrast to the MG estimator, which does not impose the poolability constraints on the slopes. The pooling across countries yields efficient and consistent estimates when the restrictions are true. However, if the slope homogeneity assumption is false, the PMG estimates become inconsistent, while the MG estimates are consistent in either case. The Hausman test allows us to test whether the homogeneity assumption is valid or not.

${ }^{13}$ Discretionary changes in tax rates and exemptions may also affect tax revenues, but these changes are typically not as frequent as discretionary expenditure measures, making tax revenues more closely linked to the cycles than expenditures. In practice, it is common to assume zero elasticity for expenditures and unit elasticity for revenues when measuring cyclically adjusted fiscal balances (Bornhorst et al, 2011).

14 Extending the sample to earlier years was not possible due to unavailability of certain variables. For instance, the pre-1998 IRS data on federal taxes in the United States was not available at the state level.
} 


\section{B. Preliminary Evidence on Redistribution}

Figures 4-6 present graphical evidence on redistribution through fiscal transfers. For each country, they show the interquartile range of net fiscal transfers over the sample period under consideration in each state. The box plots show clear evidence of redistribution in all three countries. For example, in the U.S. (Figure 4), West Virginia, Mississippi, Maine and several other states were permanent net recipients of net fiscal transfers during 1998-2010. In West Virginia, the median annual net fiscal transfer amounted to slightly less than 20 percent of state GDP. On the opposite side of the spectrum, Minnesota, Delaware, and Connecticut (among others) were net contributors. For instance, in Minnesota the median net fiscal transfer amounted to about 15 percent of state GDP. A similar picture emerges when considering Canada and Australia. In Canada (Figure 5), Newfoundland and Labrador were the largest net recipients (with a median of 10 percent of state GDP), while Ontario was the largest net contributor (with a median of -10 percent of state GDP). Similarly, in Australia (Figure 6), Northern Territory was the largest net recipient state (with a median of 15 percent of state GDP), while Australian Capital Territory was the largest net contributor (with a median of -5 percent of state GDP).

It is important to note that notwithstanding the similarity in terms of magnitude, redistribution in these three countries is driven by different considerations. In Canada and Australia redistribution is an explicit objective of the federal government enshrined in the constitution, while in the U.S. redistribution takes place as a byproduct of revenue and spending centralization, including their progressive features. This element is further discussed below.

\section{ESTIMATION RESULTS}

This section presents estimation results based on equation (1) using the Pooled Mean Group estimator. For comparison purposes, we also report results based on Bayoumi and Masson (1995) two-step approach.

\section{A. Bayoumi and Masson (1995): Two-Step Approach}

Table 2 reports estimation results based on Bayoumi and Masson (1995) two-step approach. The purpose of this exercise is to update empirical evidence using a conventional approach used in previous studies before moving to a new and more efficient approach. Panel A shows redistribution estimates based on cross-sectional regressions between state-specific mean values of regional incomes relative to the national average (equation 6). The magnitude of redistribution (1- $\beta_{\text {redist})}$ is 28 percent and 31 percent for the U.S. and Canada, respectively. The U.S. estimate is somewhat larger than the 22 percent reported in Bayoumi and Masson, while the estimate for Canada is smaller than Bayoumi and Masson's 39 percent. At 13 percent, the redistribution effect is smallest in Australia. An important caveat here is that the results for Canada and Australia are based on a small number of observations (which is equal to the number of states in each country), which could explain the unexpectedly smaller estimate of redistribution in Australia relative to the U.S.

Panel B shows risk-sharing estimates (1- $\beta$ risk-sharing) based on panel data regressions between changes in demeaned income variables (equation 7) using the baseline and trend-augmented 
specifications. For the U.S. and Australia, the risk-sharing estimate is around 5 percent, while it is slightly higher for Canada (8 percent). Interestingly, our risk-sharing estimates for the U.S. and Canada over 1998-2010 are much smaller than those obtained in Bayoumi and Masson for the earlier sample period (1969-1986). This could be due to the fact that with an increased harmonization of regional business cycles and better functioning cross-regional financial markets, the scope for risk-sharing in these federations has declined over time.

\section{B. Pooled Mean Group Estimator: One-Step Approach}

Table 3 reports estimation results based on the PMG estimator. Columns (1)-(2) display the estimation results for the U.S. using the baseline and trend-augmented specifications, respectively. In both specifications, the magnitude of redistribution is 13 percent, which is smaller than the average 26 percent found in studies reported in Table 1 as well as the 28 percent found with the two-step methodology and more recent data. In contrast, the magnitude of risk-sharing at 11 percent is comparable to the 14 percent average found in previous studies and larger than the 5 percent number based on the two-step methodology. Compared to individual studies, our risk-sharing estimate is close to that of Von Hagen (1992), Goodhart and Smith (1993), and Obstfeld and Peri (1998) but much smaller than the 31 percent estimate reported in Bayoumi and Masson (1995).

There could be two reasons for these large differences. First, this paper uses a more recent data set. Second, Bayoumi and Masson use a two-step estimation method, which reduces the sample to the number of states (48 in their study) and more importantly abstracts from changes in redistribution over time. The one-step procedure exploits both the cross-sectional and the time variation in the redistribution effect, which should yield more efficient estimates. The results also suggest that there was no substantial increase in redistribution over time (the coefficient of the trend variable is close to zero). Finally, the speed of adjustment coefficient is quite large, suggesting that about 70 percent of the deviation from the long-run equilibrium is corrected within one year.

Columns (3)-(4) report estimation results for Canada. The magnitude of redistribution in Canada at 18-20 percent is larger than that in the U.S. This finding is consistent with the stronger redistribution mandate of the federal government in Canada, where the redistribution motive is enshrined in the constitution. Nevertheless, the redistributive effect is somewhat smaller than the average 36 percent obtained in the literature and the 31 percent obtained using the two-step methodology. Similar to the case of the U.S., the difference in estimates reflects both different estimation periods and different methodologies. The two-step pure cross-sectional method used in previous studies relies only on 10 observations in the case of Canada, a very small sample. Regarding risk-sharing, we find that fiscal transfers cushion only 4 percent of the initial regional income shock in Canada, even smaller than in the U.S. Bayoumi and Masson (1995) also obtained relatively modest risk-sharing effect in Canada. As in the case of the U.S., there is no evidence of a substantial increase in redistribution over time (the coefficient of the trend variable is close to zero). In addition, the speed of adjustment at 56-57 percent per year is also relatively large.

Columns (5)-(6) report estimation results for Australia. The magnitude of redistribution in Australia, at 22-24 percent, is the largest among the three countries and comparable to the two- 
step estimate reported in the previous section. As in the case of Canada, the large magnitude of redistribution is consistent with the federal government's mandate to reduce income inequality following the establishment of the Commonwealth in 1933 (Koutsogeorgopoulou, 2007). The risk-sharing effect (4 percent) is modest and comparable to that in Canada. ${ }^{15}$ However, the speed of adjustment coefficient is not as large as in the other two countries, suggesting that state-level incomes adjust more slowly to their long-run equilibrium level. ${ }^{16}$

\section{The Role of Individual Components of Net Fiscal Transfers in Cushioning the IMPACT OF SHOCKS}

Weaknesses in the fiscal architecture of the euro area, as evidenced during the crisis, have provoked a discussion on options to strengthen fiscal insurance against macroeconomic shocks hitting individual member states. One approach that gained traction in recent policy debates is the creation of a rainy-day fund which would collect revenues from euro area members at all times and make transfers to countries when they experience negative macroeconomic shocks (see Chapter 5 for a fuller discussion).

Motivated by these discussions, this section explores the relative role of different components of net fiscal transfers in cushioning regional income shocks in federations. These can be decomposed into gross transfers to state budgets, gross transfers to individuals, and federal tax payments. We use the following empirical specification:

$$
\left(\frac{T_{i t}}{\text { Ypot }_{i t}} * 100\right)=\alpha+\beta\left(\frac{Y_{i t}}{\bar{Y}_{t}} * 100\right)+\gamma G A P_{i t}+\mu_{i}+\lambda_{t}+\varepsilon_{i t}
$$

where $i$ and $t$ indices denote states and time, respectively. $\mu$ and $\lambda$ are state and time fixed effects, respectively. The dependent variable is the ratio of various components of net fiscal transfers (T), including gross transfers to state budgets (TRANS), gross transfers to individuals (TRANSDIR), federal taxes (TAX), and net fiscal transfers (T = TRANS + TRANSDIR - TAX), over state potential GDP. ${ }^{17}$ As transfers to state budgets are largely driven by predetermined formulas that do not account for regional cyclical fluctuations, while gross transfers to individuals and federal taxes are largely driven by automatic stabilizers and are more responsive to regional cycles, the comparison of results for each dependent variables would allow us to infer the relative

\footnotetext{
${ }^{15}$ For all three countries, we have also tried adding lagged risk-sharing variable to the specification to account for possible additional dynamic effects on top of the error correction mechanism. The coefficients of lagged variables came out insignificant while the long-run slope (redistribution) was almost unaffected. In addition, standard information criteria (Akaike, Bayes-Schwartz) provide support to a more parsimonious specification (1).

16 The smaller speed of adjustment coefficients for Australia and Canada compared to the United States ones may reflect the relative longevity of business cycles, as the latter are expected to be lengthier in commodity exporting countries.

17 State potential GDP is estimated using linear and quadratic trends, which is an equivalent of the HP filter with the smoothing parameter of 100 .
} 
importance of transfers to state budgets compared to taxes and gross transfers to individuals in cushioning regional income shocks.

There are two explanatory variables:

- The first explanatory variable measures the trend component of the relative income gap for each state, i.e. the trend component of the ratio of each state GDP over the national average GDP. ${ }^{18}$ We use the trend component of this ratio to better capture the notion of income convergence since cyclical movements do not affect income convergence over the long term. A negative coefficient $\beta$ (positive for the specification with federal taxes) would support the redistribution motive, suggesting that relatively poorer states receive more transfers and pay less taxes than richer ones.

- The second explanatory variable is the state-specific output gap. Its coefficient $\gamma$ captures the risk-sharing motive of fiscal transfers, after controlling for the stabilization motive through time fixed effects $(\lambda)$. A negative coefficient $\gamma$ (positive for the specification with federal taxes) would indicate that fiscal transfers cushion the impact of idiosyncratic shocks hitting individual states, supporting the risk-sharing motive.

Intuitively, in the long-run, the output gap is averaging to zero (i.e., positive and negative cyclical effects cancel out) and the long-run relationship between transfers and relative income gap as measured by coefficient $\beta$ captures the impact of fiscal transfers on income redistribution. Similarly, after controlling for the long-run component of fiscal transfers that contributes to redistribution, the remaining cyclical variation in fiscal transfers is associated with regional output gap through a measure of risk-sharing $\gamma$.

Our strategy is to estimate specification (2) without and with time fixed effects. In the former case, coefficient $\gamma$ measures the impact of risk-sharing and stabilization, while in the latter case it measures the impact of risk-sharing only, as the impact of common shocks is controlled for through time fixed effects. ${ }^{19}$

Table 4 presents the estimation results for Australia, Canada and the U.S. Columns (1)-(4) display the results for the specification without time fixed effects, while columns (5)-(8) display the results for the specification with time fixed effects. The results can be summarized as follows:

- Transfers to state budgets. There is weak evidence on the importance of transfers to state budgets in cushioning the impact of regional shocks. Only in Australia and Canada do transfers to state budgets have a significant albeit small (7-8 percent) impact on

\footnotetext{
18 Measured as the real GDP per capita trend in each state divided by its country-wide average in each period. The trend component is estimated using a quadratic trend.

${ }^{19}$ As a robustness check, we have replaced time fixed effects with national output gaps to control for common shocks in specification (2). The results on the sizeable effect of stabilization are qualitatively similar and are available from the authors upon request.
} 
redistribution ( $\beta$ ). This is consistent with the stronger redistribution mandate of the federal government in these countries relative to the U.S. There is largely no significant association between transfers to state budgets and regional cycles $(\gamma)$, suggesting a limited role of these transfers for risk-sharing.

- Gross transfers to individuals. In contrast, there is strong evidence in support of the hypothesis that gross transfers to individuals contribute to redistribution and risk-sharing. The impact on redistribution (12-16 percent) is much stronger than the impact on risksharing (7 percent). Moreover, the significant impact on gross transfers to individuals on risksharing vanishes when controlling for time fixed effects (common shocks), suggesting that these transfers serve an important stabilization role. Again, the limited evidence on risksharing is consistent with the more conventional approach used in the previous section.

- Federal taxes. Similar to gross transfers to individuals, federal taxes have significant impact on risk-sharing in the U.S. (21 percent) and Australia (17 percent), but do not significantly affect redistribution. The large size of the coefficients further confirms the important role played by these transfers for risk-sharing.

- Net fiscal transfers. When combining the net effect of all fiscal transfers into one variable, we find that in net terms fiscal transfers have significant impact on risk-sharing and redistribution in all three federations. However, when time fixed effects are included in the specification (columns 5-8), the coefficient on the output gap variable ( $\gamma$ ) turns insignificant in Australia and Canada, and decreases in magnitude in the U.S. ${ }^{20}$ This result indicates that the stabilization motive of net fiscal transfers plays an important role in all three countries. Thus, not controlling for it may provide a misleading picture of the impact of risk-sharing (in line with Von Hagen's criticism). The impact of net fiscal transfers on stabilization can be estimated as the difference between coefficients $\gamma$ in columns (4) and (1). ${ }^{21}$ The magnitude of stabilization in the U.S. (16 percent), Canada (14 percent), and Australia (23 percent) is quite sizeable and exceed that of risk-sharing.

Overall, the analysis of individual components of net fiscal transfers suggests that transfers to state budgets play a limited role in cushioning the impact of regional shocks. The significant impact of net transfers mostly comes from gross transfers to individuals and federal taxes. Furthermore, the results suggest that federal governments' response to common shocks (stabilization) is stronger than their response to regional shocks (risk-sharing). In both cases, the response is largely driven by automatic stabilizers (gross transfers to individuals and federal

\footnotetext{
${ }^{20}$ A separate analysis of the relative importance of common and idiosyncratic shocks suggests that regional cycles are more synchronized in Australia and Canada than in the United States. The greater synchronization of regional cycles in Australia and Canada could explain the insignificant impact of automatic stabilizers when common shocks are controlled for.

${ }^{21}$ In this calculation, the coefficients that are not statistically significant are set equal to zero.
} 
taxes) rather than the relatively less cyclical component of net fiscal transfers (transfers to state budgets). However, the latter has a significant impact on redistribution in Canada and Australia.

\section{CONCLUSIONS}

All three methodologies used point to some common results:

- Net fiscal transfers have a larger impact on stabilization than on risk sharing. The moderate impact on risk-sharing is modest, ranging between 4 percent in Australia and Canada and 11 percent in the U.S. Previous studies found similarly moderate estimates of risk-sharing. This could be due to the fairly synchronized business cycles and enhanced private risksharing facilitated by fiscal centralization. The impact of fiscal transfers on stabilization (that is, the response to common shocks) is larger. This suggests that net fiscal transfers have been more responsive to common shocks than to idiosyncratic shocks in the three federations under study. The responsiveness of net fiscal transfers to common shocks can benefit weaker economies more than stronger ones, as the latter have easier access to financial markets.

- The impact of fiscal transfers is mainly channeled through the establishment of cyclicallysensitive revenue and spending functions at the center. To the extent that these central revenue and spending functions are transferred from local governments, the overall countercyclical response of transfers (central plus local) will not change, and ceteris paribus the ability of states to cushion the impact of shocks will not improve greatly following centralization. This said, transferring to the center some cyclical spending and revenues can help if, for some reason, the local automatic stabilizers are not able to operate fully either because of local fiscal rules or because of financing constraints. These two issues are discussed, respectively, in Chapter 3 and Chapter 5 of this book.

- Net fiscal transfers also have an impact on redistribution, ranging between 13 percent in the U.S. and 24 percent in Australia. Interestingly, the evidence on redistribution is found not only in Australia and Canada, where the constitution provides an explicit redistribution mandate to the federal government, but also in the U.S. This finding suggests that redistribution occur as a consequence of centralization of revenue and expenditure policies. ${ }^{22}$

What are the implications of these findings? The fact that net fiscal transfers from the center play a relatively modest role in offsetting common and (especially) idiosyncratic shocks in the three federations considered may be due to various reasons. It may suggest that the arguments in favor of risk-pooling are in practice outweighed by other considerations (as discussed in Section

\footnotetext{
22 To avoid persistent transfers that are redistributive, the transfer system should only offset transitory shocks. The problem is that policymakers do not know whether a shock is transitory or persistent in real time and hence it is difficult to design a transfer scheme targeted to transitory shocks only. Furthermore, it can be shown that schemes that do not take into account the risk profile of countries-for example one where all countries contribute the same share of their GDP-generally lead to permanent transfers.
} 
II). However, it may also imply that fiscal centralization in existing federations has facilitated the synchronization of business cycles and diminished the significance of regional shocks.

The case for enhancing fiscal risk-sharing would be stronger for currency unions like the euro zone, where economic cycles are less synchronized and where fiscal centralization can further enhance private risk-sharing mechanisms (through promotion of financial sector integration and creation of a central deposit insurance for example).

This could be achieved in various ways. One option is to set up an ad hoc rainy-day fund that transfer resources to states hit by shocks. An alternative, most commonly used in existing federations, is the centralization of some spending and revenue functions that are sensitive to the economic cycle (e.g., unemployment insurance and taxes). The common provision of public services can also prevent unduly procyclical fiscal behavior in cases when the local automatic stabilizers cannot operate fully, either because of local fiscal rules or because of financing constraints. Over the long run, the establishment of a central budget would reduce the risk of idiosyncratic fiscal policies at the state level. The larger is the share of the spending responsibilities that are centralized, the lower is the likelihood that large fiscal imbalances will arise at the local level. Finally, centralization would allow for a much better coordination of fiscal policy in response to common shocks, and-of course-for a larger countercyclical response at the central level (Cottarelli, 2013). 


\section{REFERENCES}

Andersson, L., 2004, "Regional Risk-Sharing Provided by the Fiscal System: Empirical Evidence from Sweden," Regional Studies, 38 (3): pp. 269-80.

Bayoumi, T., and Masson, P., 1995, "Fiscal Flows in the United States and Canada: Lessons from Monetary Union in Europe," European Economic Review, 39: pp. 253-74.

Bayoumi, T. and Masson, P., 1998, "Liability-Creating versus Non-Liability-Creating Fiscal Stabilization Policies: Ricardian Equivalence, Fiscal Stabilization, and EMU", Economic Journal, 108: pp. 102645.

Beetsma, R. and Debrun, X., 2004, "The Interaction Between Monetary and Fiscal Policies in a Monetary Union: A Review of Recent Literature", In Monetary Policy, Fiscal Policies, and Labor Markets: Macroeconomic Policymaking in the EMU, ed. Roel Beetsma, (Cambridge University Press, Cambridge, UK).

Bornhorst, F., Dobrescu, G., Fedelino, A., Gottschalk, J., and Nakata, T., 2011, "When and How to Adjust Beyond the Business Cycle? A Guide to Structural Fiscal Balances," Technical Guidance Note, Fiscal Affairs Department (Washington: International Monetary Fund).

Cottarelli, C., 2013, "European Fiscal Union: A Vision for the Long Run," Swiss Journal of Economics and Statistics, 149 (2): pp. 167-174.

Decressin, J., 2002, "Regional Income Redistribution and Risk-Sharing: How Does Italy Compare in Europe?" Journal of Public Economics, 86: pp. 287-306.

European Commission, 1977, "Report of the Study Group on the Role of Public Finances in European Integration" (MacDougall Report), (Brussels: European Commission).

Friedman, M., 1957, A Theory of the Consumption Function, Princeton, N.J. (Princeton University Press).

Goodhart, C., and Smith, S., 1993, "Stabilization," In The Economics of Community Public Finance, European Economy Reports and Studies, 5: 417-55 (Brussels: European Commission).

Hamada, K., 1985, The Political Economy of International Monetary Interdependence (MIT Press, Cambridge, MA).

Koutsogeorgopoulou, V., 2007, "Fiscal Relations Across Levels of Government in Australia," OECD Economics Department Working Paper No. 541 (Paris: OECD).

Masson, P. and Taylor, M., 1993, "Fiscal Policy within Common Currency Areas," Journal of Common Market Studies, 31 (1): pp. 29-44. 
Melitz, J., and Zumer, F., 2002, "Regional Redistribution and Stabilization by the Centre in Canada, France, the U.K. and the U.S.: A Reassessment and New Tests," Journal of Public Economics, 86 (2): pp. 263-84.

Obstfeld, M., and Peri, G., 1998, "Regional Non-Adjustment and Fiscal Policy," Economic Policy, 26: pp. 205-69.

Pesaran, H., Shin, Y., and Smith, R., 1999, "Pooled Mean Group Estimation of Dynamic Heterogeneous Panels," Journal of the American Statistical Association, 94: pp. 621-34.

Sachs, J. and Sala-i-Martin, X., 1992, "Fiscal Federalism and Optimum Currency Areas: Evidence for Europe from the United States", In Establishing a Central Bank: Issues in Europe and Lessons from the U.S., ed. Matthew Canzoneri, Vittorio Grilli, and Paul Masson, (Cambridge: Cambridge University Press).

Von Hagen, J., 1992, "Fiscal Arrangements in a Monetary Union: Evidence from the US", In Fiscal Policy, Taxes, and the Financial System in an Increasingly Integrated Europe, ed. Don Fair and Christian de Boissieux, (Kluwer, London). 


\section{ANNEX 1. EMPIRICAL APPROACHES USED IN EXISTING LITERATURE TO QUANTIFY THE IMPACT OF FISCAL TRANSFERS}

This Annex provides a brief overview of three main empirical approaches used in existing studies to quantify the impact of fiscal transfers by Sachs and Sala-i-Martin (1992), Von Hagen (1992), and Bayoumi and Masson (1995).

Sachs and Sala-i-Martin (1992) approach

One of the first empirical studies trying to quantify the impact of fiscal transfers is Sachs and Sala-i-Martin (1992). ${ }^{23}$ The authors start from the definition of changes in the disposable income: $\Delta Y D=\Delta Y-\Delta T X+\Delta T R$, where $Y D$ is the regional disposable income, $Y$ is the regional GDP, $T X$ denotes regional taxes paid to the federal budget, and TR denotes gross fiscal transfers from the federal government (all variables are expressed in real per capita terms). Further, they assume that changes in TX and TR are affected by changes in regional GDP through the working of automatic stabilizers. They define $\beta_{T X}=\frac{\Delta T X}{\Delta Y} \frac{Y}{T X}$ and $\beta_{T R}=\frac{\Delta T R}{\Delta Y} \frac{Y}{T R}$ as elasticities of taxes and fiscal transfers with respect to GDP and rewrite the disposable income identity as:

$$
\Delta Y D=\Delta Y-\beta_{T X} \frac{T X}{Y} \Delta Y+\beta_{T R} \frac{T R}{Y} \Delta Y=\Delta Y * \lambda
$$

where $\lambda=\left(1-\beta_{T X} \frac{T X}{Y}+\beta_{T R} \frac{T R}{Y}\right)$ measures the effect of net fiscal transfers on the regional disposable income. To assess the magnitude of elasticities $\beta$, the authors run the following regressions:

$$
\begin{aligned}
& \log \left(\frac{T X_{i t}}{\overline{T X_{t}}}\right)=\alpha_{T X}+\beta_{T X} \log \left(\frac{Y_{i t}}{\bar{Y}_{t}}\right)+\gamma_{T X} \text { trend }+\varepsilon_{i t} \\
& \log \left(\frac{T R_{i t}}{\overline{T R}_{t}}\right)=\alpha_{T R}+\beta_{T R} \log \left(\frac{Y_{i t}}{\bar{Y}_{t}}\right)+\gamma_{T R} \text { trend }+u_{i t}
\end{aligned}
$$

where $i$ and $t$ indices denote region and time, respectively, and $\overline{T X}_{t}, \overline{T R}_{t}$, and $\bar{Y}_{t}$ are national averages of respective variables in period $t$. The authors employ this methodology to quantify the impact of fiscal transfers in 9 U.S. regions for the period 1970-80.

Von Hagen (1992): two-step approach

The main issue with the empirical approach of Sachs and Sala-i-Martin (1992) is that it only assesses the overall impact of fiscal transfers, but does not distinguish between redistribution and insurance motives. Von Hagen (1992) attempts to address this issue by using the following regressions:

$$
\Delta \log \left(T X_{i t}\right)=\alpha_{i}+\theta_{T X} \Delta \log \left(Y_{i t}\right)+D_{\text {Oil }}+\gamma_{t}+\varepsilon_{i t}
$$

\footnotetext{
23 The role of fiscal transfers in offsetting long-run regional income differentials and cushioning regional shocks was recognized earlier in the MacDougall Report (Commission of the European Communities, 1977). However, the discussion in this report was largely qualitative rather than quantitative.
} 


$$
\Delta \log \left(T R_{i t}\right)=\alpha_{i}+\theta_{T R} \Delta \log \left(Y_{i t}\right)+D_{O i l}+\gamma_{t}+\varepsilon_{i t}
$$

where $i$ and $t$ indices denote region and time, respectively, Doil are dummies for three oilproducing states of the U.S. (Alaska, Oklahoma, Wyoming), $\alpha_{i}$ are regional fixed effects to control for state-specific unobserved characteristics, and $\gamma_{t}$ are time fixed effects to control for common shocks. Coefficients $\theta_{T x}$ and $\theta_{T R}$ are used to measure the risk-sharing effects of federal taxes and transfers, respectively. In Von Hagen's specification, the impact of aggregate shocks is controlled for by time fixed effects. ${ }^{24}$ Von Hagen applies this methodology to study the impact of fiscal transfers on risk-sharing in 48 states in the U.S. over the period 1981-86. Von Hagen also conducts cross-sectional regression on regional average variables to assess the impact on redistribution.

Bayoumi and Masson (1995): two-step approach

Unlike the previous two authors, Bayoumi and Masson (1995) do not distinguish between effects of federal taxes and transfers separately and assess their combined effect. Similar to Von Hagen (1992), they adopt a two-step approach for measuring redistribution and risk-sharing effects of fiscal transfers by running the following regressions:

$$
\begin{gathered}
\left(\frac{\overline{Y D}_{i}}{\overline{\overline{Y D}}}\right)=\alpha+\beta_{\text {redist }}\left(\frac{\bar{Y}_{i}}{\overline{\bar{Y}}}\right)+\varepsilon_{i} \\
\Delta\left(\frac{Y D_{i t}}{\overline{Y D}_{t}}\right)=\alpha_{i}+\beta_{\text {risk-sharing }} \Delta\left(\frac{Y_{i t}}{\bar{Y}_{t}}\right)+u_{i t}
\end{gathered}
$$

where $i$ and $t$ indices denote region and time, respectively, $\overline{Y D}_{i}$ and $\bar{Y}_{i}$ are state-specific averages of respective variables over the sample, $\overline{Y D}_{t}$ and $\bar{Y}_{t}$ are national averages of respective variables in period $t$, and $\overline{\overline{Y D}}$ and $\overline{\bar{Y}}$ are national averages of respective variables over the whole sample.

The slope coefficient from the first regression is used to measure the impact of redistribution (1$\beta_{\text {redist }}$. It is obtained from a cross sectional relationship between state-specific mean values of regional incomes relative to the national average, which are free from short term fluctuations driven by idiosyncratic shocks. The slope coefficient from the second regression is used to measure the impact of risk-sharing (1-Brisk-sharing). It is obtained from a panel regression of changes of state-specific regional incomes relative to the national average, which filters out the impact of long-term trends in both variables. It is important to note that unlike time fixed effects used in Von Hagen (1992), in this approach the impact of common shocks is controlled for by demeaning regional disposable income and GDP by their national averages (within transformation). The authors apply this methodology to study the impact of fiscal transfers on risk-sharing and redistribution in the states of the U.S. and Canadian provinces over the period 1969-1986.

\footnotetext{
24 The literature does not quantify the impact of fiscal transfers on stabilization. Instead, it controls for the stabilization effect by using either time effects (e.g., Von Hagen, 1992) or by demeaning variables used in the regressions (e.g., Bayoumi and Masson, 1995) and assesses the impact of fiscal transfers on redistribution and risk-sharing.
} 
The comparison of these three empirical approaches points to some pitfalls associated with each of them. The Sachs and Sala-i-Martin's approach can be used to evaluate the overall impact of fiscal transfers on redistribution and risk-sharing, but does not allow distinguishing between the two. The Von Hagen and Bayoumi and Masson approaches attempt to address this issue by running cross-sectional regressions on average variables (redistribution) and using time fixed effects and demeaning variables in panel regressions, respectively (risk-sharing). However, these approaches are inefficient as averaging substantially limits the degrees of freedom for statistical inference, especially in federations with small number of states (e.g., Canada). Therefore, in addition to the conventional two-step approach, we report results based on a one-step approach that addresses the efficiency issue and estimates the impact of fiscal transfers on redistribution and risk-sharing simultaneously. 


\section{ANNEX 2. DATA DESCRIPTION AND SOURCES}

\section{Macroeconomic variables}

\section{GDP}

Australia - Australia Bureau of Statistics, from 1990 to 2011.

Canada - Department of Finance, from 1990 to 2010.

USA - US Census Bureau, from 1997 to 2010.

CPI

Australia - Australia Bureau of Statistics, from 1990 to 2011, country-level.

Canada - Department of Finance, from 1990 to 2011, country-level.

USA - US Census Bureau, from 1990 to 2010, country-level.

\section{Population}

Australia - Australia Bureau of Statistics, from 1990 to 2011.

Canada - Department of Finance, from 1990 to 2010.

USA - US Census Bureau, from 1990 to 2010.

\section{Fiscal variables}

Gross transfers from central government to state budgets

Australia - Australia Bureau of Statistics, from 1999 to 2011.

Canada - Department of Finance, from 1990 to 2011.

USA - US Census Bureau, from 1990 to 2010.

\section{Gross transfers from central government to individuals}

Australia - Australian Bureau of Statistics, Australian National Accounts table 5220.0, from 1998 to 2011.

Canada - Statistics Canada, Provincial and Territorial Economic Accounts, from 1990 to 2009. USA - Bureau of Economic Analysis (BEA), from 1998 to 2010.

\section{Taxes paid to central government}

Australia - Australian Bureau of Statistics, Australian National Accounts table 5220.0, from 1998 to 2011.

Canada - Statistics Canada, Provincial and Territorial Economic Accounts, from 1990 to 2009. USA -Internal Revenue Service (IRS), 1998 to 2010. 
Table 1. Empirical Estimates of Redistribution and Risk-sharing from Previous Studies

\begin{tabular}{|c|c|c|c|c|}
\hline \multirow[t]{2}{*}{ Study } & \multirow[t]{2}{*}{ Country } & \multirow[t]{2}{*}{ Sample period } & \multicolumn{2}{|c|}{ Federal fiscal flows } \\
\hline & & & Redistribution & Risk-sharing \\
\hline Sachs and Sala-i-Martin (1992) & USA & $1970-80$ & \multicolumn{2}{|c|}{$33--40$} \\
\hline Masson and Taylor (1993) & Canada & $1965-88$ & \multicolumn{2}{|c|}{13} \\
\hline Andersson (2004) & Sweden & $1983-2001$ & \multicolumn{2}{|c|}{$7--22$} \\
\hline von Hagen (1992) & USA & $1981-86$ & 47 & 10 \\
\hline \multirow[t]{3}{*}{ Goodhart and Smith (1993) } & Canada & $1966-88$ & 15 & 17 \\
\hline & UK & $1984-87$ & 21 & 21 \\
\hline & USA & $1982-86$ & 13 & 11 \\
\hline \multirow[t]{2}{*}{ Bayoumi and Mason (1995) } & Canada & $1969-86$ & 39 & 31 \\
\hline & USA & $1969-86$ & 22 & 17 \\
\hline Decressin (2002) & Italy & $1970-95$ & $25--35$ & $10--15$ \\
\hline \multirow[t]{4}{*}{ Melitz and Zumer (2002) } & Canada & $1965-88$ & 16 & $10--15$ \\
\hline & France & $1973-89$ & 38 & 20 \\
\hline & UK & $1971-93$ & 26 & 20 \\
\hline & USA & $1977-92$ & 16 & 20 \\
\hline \multirow[t]{3}{*}{ Obstfeld and Peri (1998) } & Canada & $1971-95$ & 53 & 13 \\
\hline & Italy & $1979-93$ & 8 & 3 \\
\hline & USA & $1969-85$ & 19 & 10 \\
\hline
\end{tabular}

Source: Authors, based on the literature search. Numbers in the middle of the redistribution and risk-sharing columns refer to the combined effect of the two for studies that do not disentangle between them. 
Table 2. Estimation Results Based on Bayoumi and Masson (1995) Two-step Approach

\begin{tabular}{lccc} 
A. Redistribution & $\left(\frac{\overline{\boldsymbol{Y D}}_{i}}{\overline{\overline{\boldsymbol{Y}}}}\right)=\boldsymbol{\alpha}+\boldsymbol{\beta}_{\text {redist }}\left(\frac{\overline{\boldsymbol{Y}}_{i}}{\overline{\overline{\boldsymbol{Y}}}}\right)+\boldsymbol{\varepsilon}_{i}$ & \\
\hline & USA & Canada & Australia \\
\cline { 2 - 4 } & $(1)$ & $(2)$ & $(3)$ \\
\hline b_redist & $0.72 * * *$ & $0.69 * * *$ & $0.87 * * *$ \\
& $(0.030)$ & $(0.050)$ & $(0.154)$ \\
Constant & $0.28 * * *$ & $0.31 * * *$ & 0.13 \\
& $(0.030)$ & $(0.051)$ & $(0.135)$ \\
\hline \# of obs. & 48 & 10 & 8 \\
R-squared & 0.92 & 0.87 & 0.82 \\
\hline
\end{tabular}

B. Risk-sharing

$$
\Delta\left(\frac{Y D_{i t}}{\overline{Y D}_{t}}\right)=\alpha_{i}+\beta_{\text {risk-sharing }} \Delta\left(\frac{Y_{i t}}{\bar{Y}_{t}}\right)+\gamma \text { Trend }+u_{i t}
$$

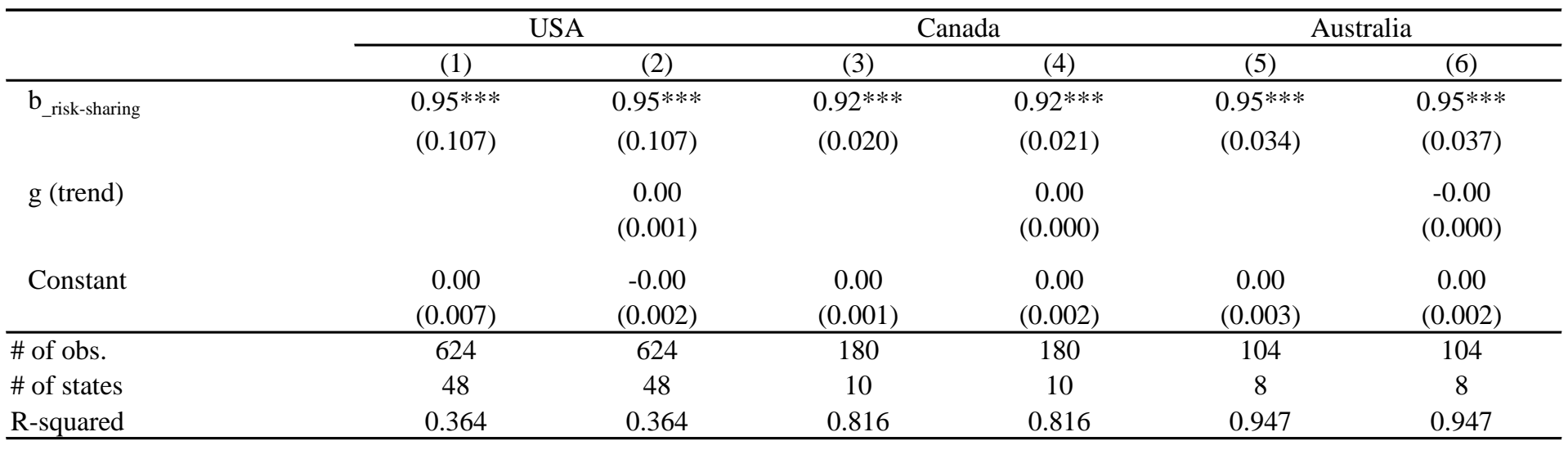

Note: YD denotes the real per capita disposable income, and Y denotes the real per capita GDP. Estimations in Panel A are performed using a crosssectional OLS, while estimations in Panel B are performed using the fixed-effects OLS estimator. Robust clustered standard errors are in parentheses. $* * *, * *$, and ${ }^{*}$ denote significance at 1,5 , and 10 percent confidence level, respectively. 
Table 3. Estimation Results Based on the Pooled Mean Group (PMG) Estimator

$$
\Delta\left(\frac{Y D_{i t}}{\overline{Y D}_{t}}\right)=\phi_{i}\left[\frac{Y D_{i t-1}}{\overline{Y D}_{t-1}}-\alpha-\beta \frac{Y_{i t-1}}{\bar{Y}_{t-1}}-\gamma \text { Trend }\right]+\delta_{i} \Delta\left(\frac{Y_{i t}}{\bar{Y}_{t}}\right)+\mu_{i}+\varepsilon_{i t}
$$

\begin{tabular}{|c|c|c|c|c|c|c|}
\hline & \multicolumn{2}{|c|}{ USA } & \multicolumn{2}{|c|}{ Canada } & \multicolumn{2}{|c|}{ Australia } \\
\hline & (1) & (2) & (3) & (4) & (5) & (6) \\
\hline \multicolumn{7}{|l|}{ Long-run coeff. } \\
\hline b (redistribution) & $\begin{array}{c}0.87 * * * \\
{[0.01]}\end{array}$ & $\begin{array}{l}0.87 * * * \\
{[0.01]}\end{array}$ & $\begin{array}{c}0.82 * * * \\
{[0.02]}\end{array}$ & $\begin{array}{l}0.80 * * * \\
{[0.02]}\end{array}$ & $\begin{array}{c}0.78 * * * \\
{[0.03]}\end{array}$ & $\begin{array}{l}0.76 * * * \\
{[0.02]}\end{array}$ \\
\hline $\mathrm{g}($ trend $)$ & & $\begin{array}{l}0.00 * * * \\
{[0.00]} \\
\end{array}$ & & $\begin{array}{r}0.00 \\
{[0.00]} \\
\end{array}$ & & $\begin{array}{l}-0.00 * * * \\
{[0.00]}\end{array}$ \\
\hline Speed of adjustment & $\begin{array}{c}-0.70 * * * \\
{[0.04]} \\
\end{array}$ & $\begin{array}{l}-0.70 * * * \\
{[0.04]}\end{array}$ & $\begin{array}{c}-0.57 * * * \\
{[0.08]} \\
\end{array}$ & $\begin{array}{c}-0.56 * * * \\
{[0.08]} \\
\end{array}$ & $\begin{array}{c}-0.31 * * * \\
{[0.06]} \\
\end{array}$ & $\begin{array}{c}-0.38 * * * \\
{[0.09]}\end{array}$ \\
\hline $\begin{array}{l}\text { Short-run coeff. } \\
\text { d (risk-sharing) }\end{array}$ & $\begin{array}{c}0.89 * * * \\
{[0.04]}\end{array}$ & $\begin{array}{l}0.89 * * * \\
{[0.04]}\end{array}$ & $\begin{array}{c}0.96 * * * \\
{[0.03]} \\
\end{array}$ & $\begin{array}{l}0.96 * * * \\
{[0.02]}\end{array}$ & $\begin{array}{c}0.96 * * * \\
{[0.03]} \\
\end{array}$ & $\begin{array}{l}0.96 * * * \\
{[0.03]} \\
\end{array}$ \\
\hline \# of obs. & 624 & 624 & 180 & 180 & 104 & 104 \\
\hline \# of states & 48 & 48 & 10 & 10 & 8 & 8 \\
\hline Hausman test (p-value) & 0.39 & 0.88 & 0.34 & 0.85 & 0.11 & 0.76 \\
\hline
\end{tabular}

Note: YD denotes the real per capita disposable income, and Y denotes the real per capita GDP. Estimations are performed using the PMG estimator of Pesaran et al. (1999). Estimations include province-specific fixed effects. Robust clustered standard errors are in parentheses. Reported short-term and speed of adjustment coefficients represent averages of state-specific estimates. Intercept is included in the long-run specification but not reported. Sample periods are: Australia (19982010), Canada (1992-2009), and USA (1998-2010). ***, **, and * denote significance at 1, 5, and 10 percent confidence level, respectively. 
Table 4. Estimation Results Using an Alternative Specification to Assess the Impact of Stabilization and Risk-sharing

\begin{tabular}{|c|c|c|c|c|c|c|c|c|}
\hline & \multicolumn{4}{|c|}{ Without time fixed effects } & \multicolumn{4}{|c|}{ With time fixed effects (controlling for stabilization) } \\
\hline & $\begin{array}{c}\text { Transfers to } \\
\text { state budgets }\end{array}$ & $\begin{array}{l}\text { Gross transfers } \\
\text { to individuals }\end{array}$ & Federal taxes & $\begin{array}{c}\text { Net federal } \\
\text { transfers }\end{array}$ & $\begin{array}{l}\text { Transfers to } \\
\text { state budgets }\end{array}$ & $\begin{array}{l}\text { Gross transfers } \\
\text { to individuals }\end{array}$ & Federal taxes & $\begin{array}{c}\text { Net federal } \\
\text { transfers }\end{array}$ \\
\hline & (1) & (2) & (3) & (4) & (5) & (6) & (7) & $(8)$ \\
\hline & \multicolumn{8}{|c|}{ USA } \\
\hline Relative real per capita income (b) & $\begin{array}{c}-0.01 \\
(-0.63)\end{array}$ & $\begin{array}{l}-0.12 * * \\
(-2.17)\end{array}$ & $\begin{array}{c}0.01 \\
(0.10)\end{array}$ & $\begin{array}{c}-0.13^{* *} \\
(-2.11)\end{array}$ & $\begin{array}{l}-0.01 \\
(-1.10)\end{array}$ & $\begin{array}{c}-0.12 * * * \\
(-7.19)\end{array}$ & $\begin{array}{c}0.00 \\
(0.15)\end{array}$ & $\begin{array}{c}-0.13 * * * \\
(-3.05)\end{array}$ \\
\hline State output gap (g) & $\begin{array}{l}-0.01 \\
(-1.33)\end{array}$ & $\begin{array}{c}-0.07 * * * \\
(-6.21)\end{array}$ & $\begin{array}{l}0.21 * * \\
(2.51)\end{array}$ & $\begin{array}{c}-0.28 * * * \\
(-3.13)\end{array}$ & $\begin{array}{l}0.02 * * \\
(2.20)\end{array}$ & $\begin{array}{c}0.01 \\
(0.95)\end{array}$ & $\begin{array}{c}0.15^{* * *} \\
(3.11)\end{array}$ & $\begin{array}{l}-0.12^{* *} \\
(-2.50)\end{array}$ \\
\hline Constant & $\begin{array}{c}4.50^{* * *} \\
(3.11)\end{array}$ & $\begin{array}{c}24.75 * * * * \\
(4.46)\end{array}$ & $\begin{array}{c}15.07 * * * \\
(3.08)\end{array}$ & $\begin{array}{l}14.17 * * \\
(2.22)\end{array}$ & $\begin{array}{c}4.55^{* * * *} \\
(5.83)\end{array}$ & $\begin{array}{c}25.19 * * * \\
(14.98)\end{array}$ & $\begin{array}{c}17.09 * * * \\
(5.19)\end{array}$ & $\begin{array}{c}12.65^{* * * *} \\
(2.88)\end{array}$ \\
\hline \# of obs. & 672 & 672 & 672 & 672 & 672 & 672 & 672 & 672 \\
\hline \# of states & 48 & 48 & 48 & 48 & 48 & 48 & 48 & 48 \\
\hline \multirow[t]{2}{*}{ R-squared } & 0.269 & 0.458 & 0.016 & 0.352 & 0.215 & 0.628 & 0.541 & 0.609 \\
\hline & \multicolumn{8}{|c|}{ Canada } \\
\hline Relative real per capita income (b) & $\begin{array}{c}-0.08^{* * * *} \\
(-6.58)\end{array}$ & $\begin{array}{l}-0.12 * \\
(-1.97)\end{array}$ & $\begin{array}{c}-0.05 \\
(-0.76)\end{array}$ & $\begin{array}{l}-0.15^{* * * *} \\
(-16.01)\end{array}$ & $\begin{array}{c}-0.08 * * * \\
(-6.57)\end{array}$ & $\begin{array}{c}-0.12 * * * \\
(-4.88)\end{array}$ & $\begin{array}{c}-0.05 * * \\
(-2.60)\end{array}$ & $\begin{array}{c}-0.15^{* * * *} \\
(-8.30)\end{array}$ \\
\hline State output gap (g) & $\begin{array}{c}-0.02 \\
(-1.07)\end{array}$ & $\begin{array}{c}-0.07 * * * \\
(-3.25)\end{array}$ & $\begin{array}{c}0.05 \\
(1.43)\end{array}$ & $\begin{array}{l}-0.14 * \\
(-2.12)\end{array}$ & $\begin{array}{c}0.00 \\
(0.01)\end{array}$ & $\begin{array}{l}-0.01 \\
(-0.65)\end{array}$ & $\begin{array}{c}0.05 \\
(1.39)\end{array}$ & $\begin{array}{l}-0.05 \\
(-0.92)\end{array}$ \\
\hline Constant & $\begin{array}{c}15.12 * * * \\
(11.82)\end{array}$ & $\begin{array}{c}20.30 * * * \\
(3.47)\end{array}$ & $\begin{array}{l}20.06^{* *} \\
(3.13)\end{array}$ & $\begin{array}{c}15.36 * * * * \\
(16.20)\end{array}$ & $\begin{array}{c}15.71 * * * * \\
(10.29)\end{array}$ & $\begin{array}{c}19.07 * * * \\
(8.06)\end{array}$ & $\begin{array}{c}17.36 * * * \\
(10.08)\end{array}$ & $\begin{array}{c}17.43 * * * \\
(8.84)\end{array}$ \\
\hline \# of obs. & 180 & 180 & 180 & 180 & 180 & 180 & 180 & 180 \\
\hline \# of states & 10 & 10 & 10 & 10 & 10 & 10 & 10 & 10 \\
\hline \multirow[t]{2}{*}{$\underline{R \text {-squared }}$} & 0.537 & 0.571 & 0.046 & 0.497 & 0.556 & 0.679 & 0.383 & 0.518 \\
\hline & \multicolumn{8}{|c|}{ Australia } \\
\hline Relative real per capita income (b) & $\begin{array}{c}-0.07 * * * \\
(-3.75)\end{array}$ & $\begin{array}{c}-0.16^{* * * *} \\
(-6.33)\end{array}$ & $\begin{array}{l}-0.09^{*} \\
(-2.21)\end{array}$ & $\begin{array}{c}-0.14 * * \\
(-3.15)\end{array}$ & $\begin{array}{c}-0.07 * * * \\
(-7.59)\end{array}$ & $\begin{array}{c}-0.16^{* * * *} \\
(-9.97)\end{array}$ & $\begin{array}{l}-0.08 * * \\
(-2.39)\end{array}$ & $\begin{array}{c}-0.15^{* * * * *} \\
(-4.16)\end{array}$ \\
\hline State output gap (g) & $\begin{array}{l}-0.05^{*} \\
(-2.27)\end{array}$ & $\begin{array}{l}-0.01 \\
(-0.55)\end{array}$ & $\begin{array}{c}0.17 * * * \\
(3.66)\end{array}$ & $\begin{array}{c}-0.23 * * * \\
(-3.91)\end{array}$ & $\begin{array}{l}-0.01 \\
(-0.36)\end{array}$ & $\begin{array}{c}-0.01 \\
(-0.64)\end{array}$ & $\begin{array}{c}0.02 \\
(0.46)\end{array}$ & $\begin{array}{l}-0.04 \\
(-1.05)\end{array}$ \\
\hline Constant & $\begin{array}{c}15.47 * * * \\
(8.23)\end{array}$ & $\begin{array}{c}28.60 * * * \\
(11.63)\end{array}$ & $\begin{array}{c}28.28 * * * \\
(6.93)\end{array}$ & $\begin{array}{c}15.80^{* * * *} \\
(3.65)\end{array}$ & $\begin{array}{c}15.68 * * * \\
(15.79)\end{array}$ & $\begin{array}{c}27.91 * * * \\
(17.24)\end{array}$ & $\begin{array}{c}26.24 * * * \\
(7.81)\end{array}$ & $\begin{array}{c}17.35^{* * *} * \\
(5.14)\end{array}$ \\
\hline \# of obs. & 104 & 104 & 104 & 104 & 104 & 104 & 104 & 104 \\
\hline \# of states & 8 & 8 & 8 & 8 & 8 & 8 & 8 & 8 \\
\hline R-squared & 0.001 & 0.819 & 0.108 & 0.104 & 0.003 & 0.846 & 0.244 & 0.157 \\
\hline
\end{tabular}

Note: The dependent variable is the ratio of the respective measure of fiscal transfers relative to state potential output. Ypot denotes potential output Y denotes the real per capita GDP, and GAP denotes output gap (measured for each state using a quadratic trend component of real per capita GDP). Estimations are performed using the fixed effects OLS estimator. Robust clustered standard errors are in parentheses. Sample periods are: Australia (1998-2010), Canada (1992-2009), and USA (1998-2010). ${ }^{* * *},{ }^{* *}$, and * denote significance at 1, 5, and 10 percent confidence level, respectively. 
Figure 1. The Relative Magnitude of Fiscal Transfers in Australia

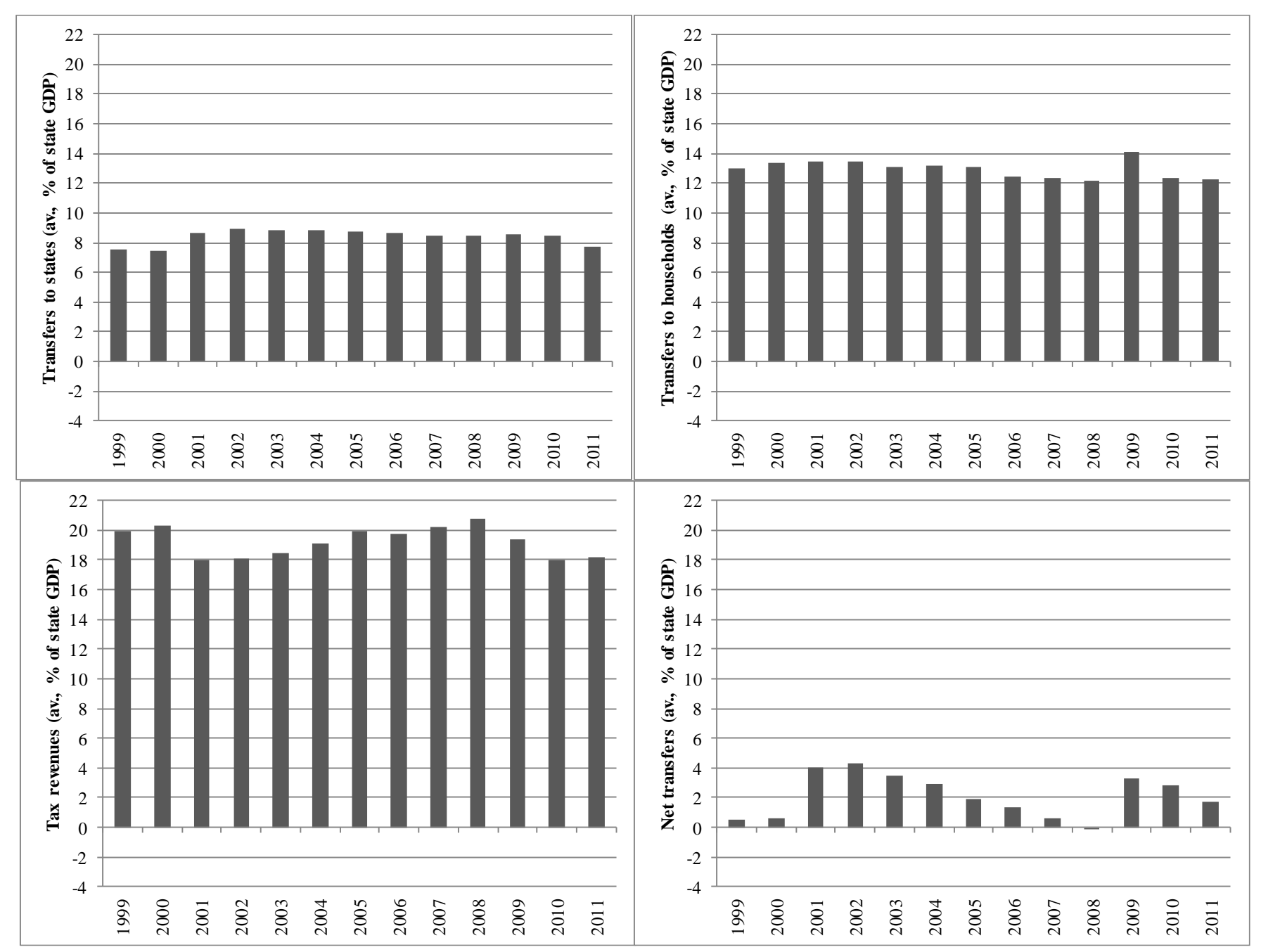

Note: Own calculations based on national sources. 
Figure 2. The Relative Magnitude of Fiscal Transfers in Canada

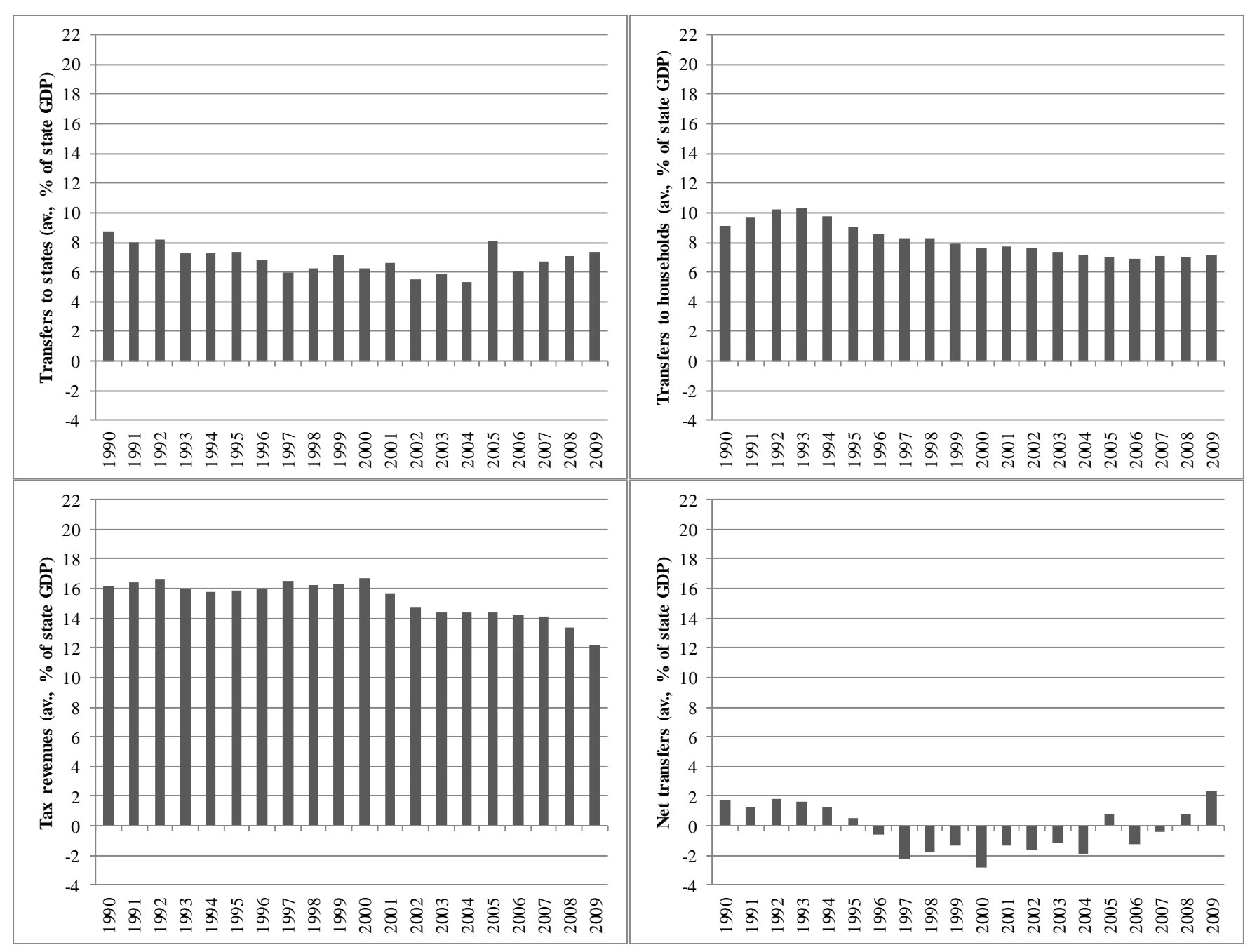

Note: Own calculations based on national sources. 
Figure 3. The Relative Magnitude of Fiscal Transfers in the U.S.

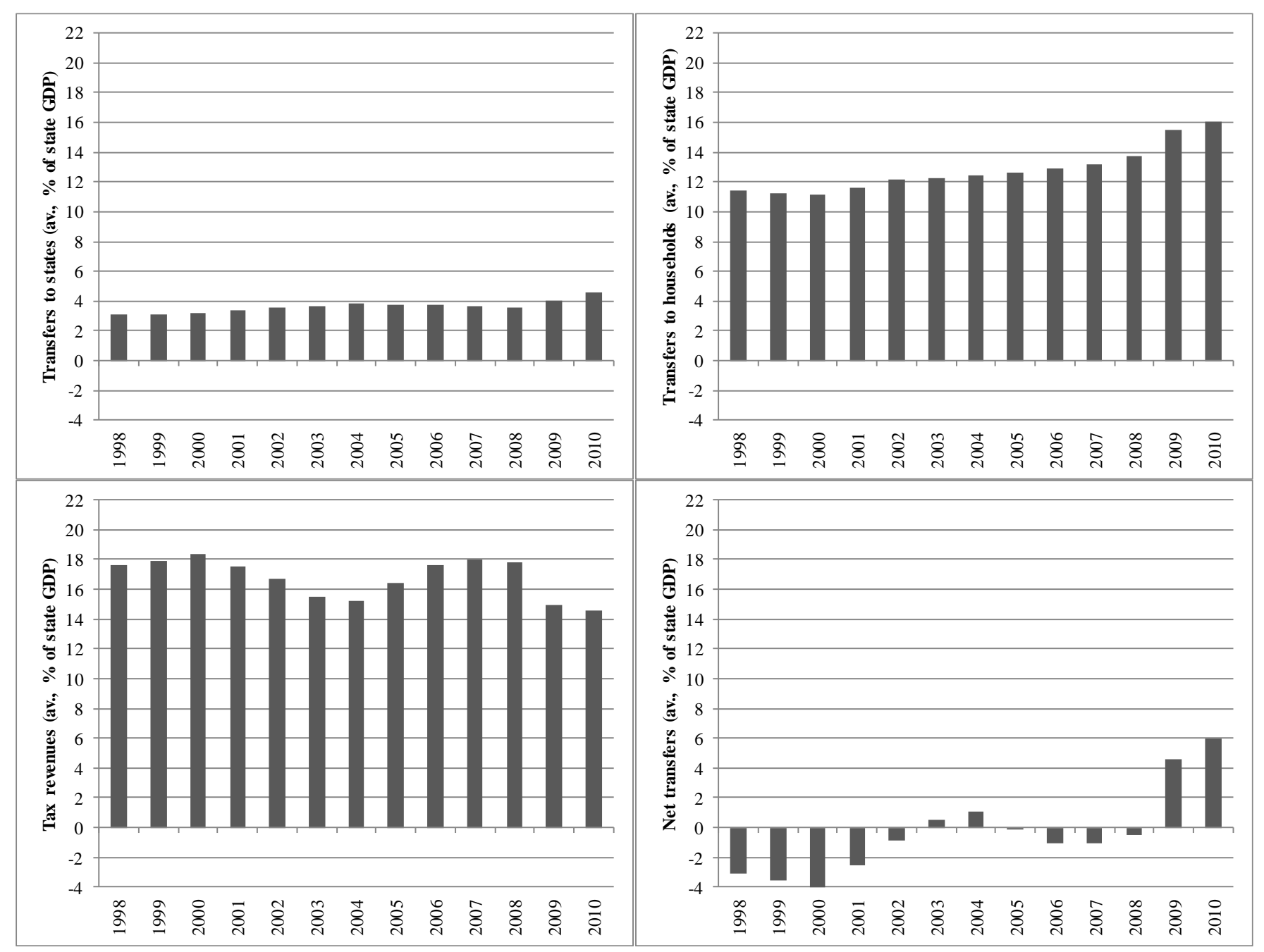

Note: Own calculations based on national sources. 
Figure 4. Redistribution through Net Fiscal Transfers in the U.S. (1998-2010)

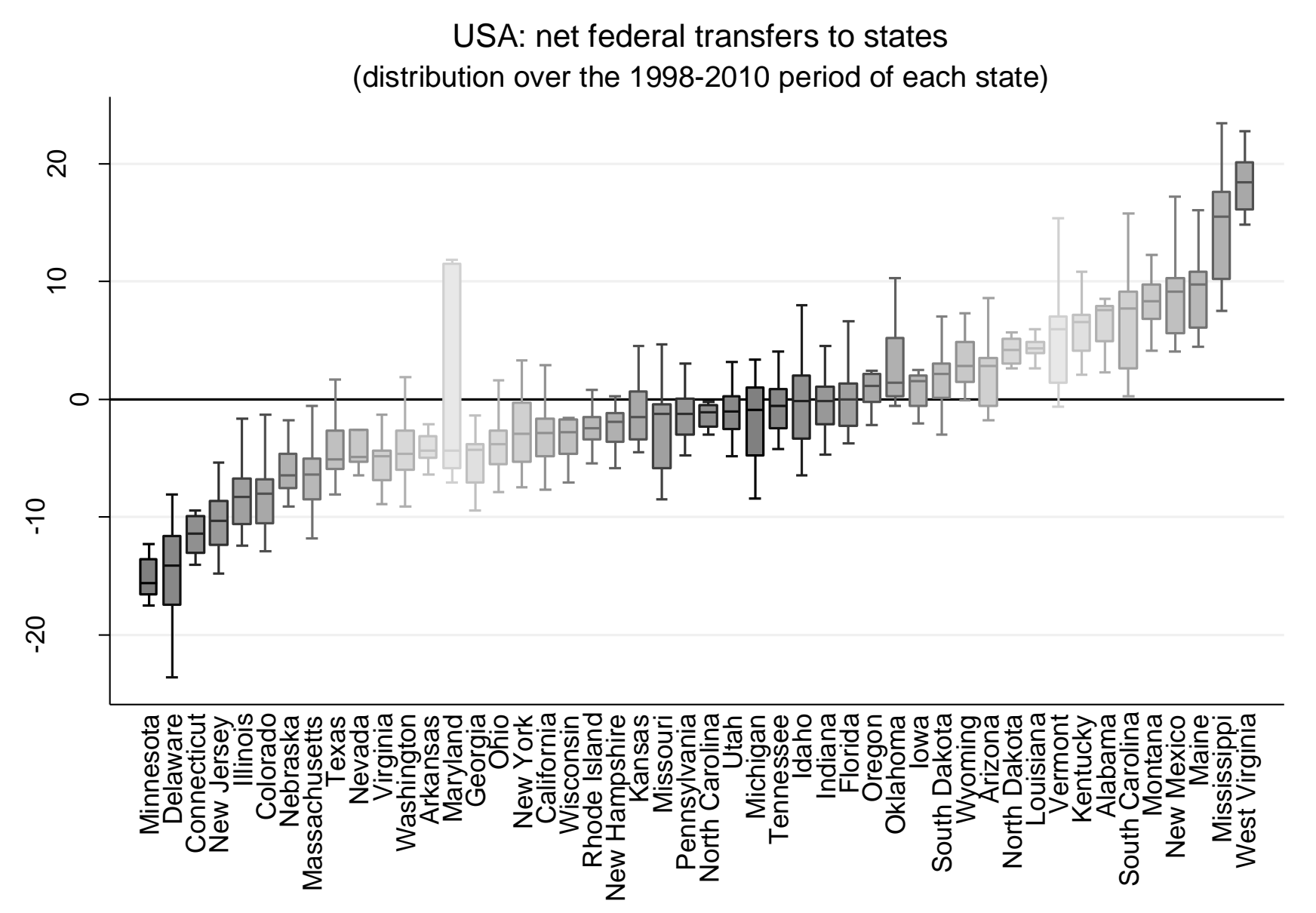

Note: The whiskers of the plot denote the minimum and maximum values of variables for each state within a country. The edges of the box denote 25 th and 75 th percentiles of the distribution. The line splitting the box denotes the median. 
Figure 5. Redistribution through Net Fiscal Transfers in Canada (1992-2009)

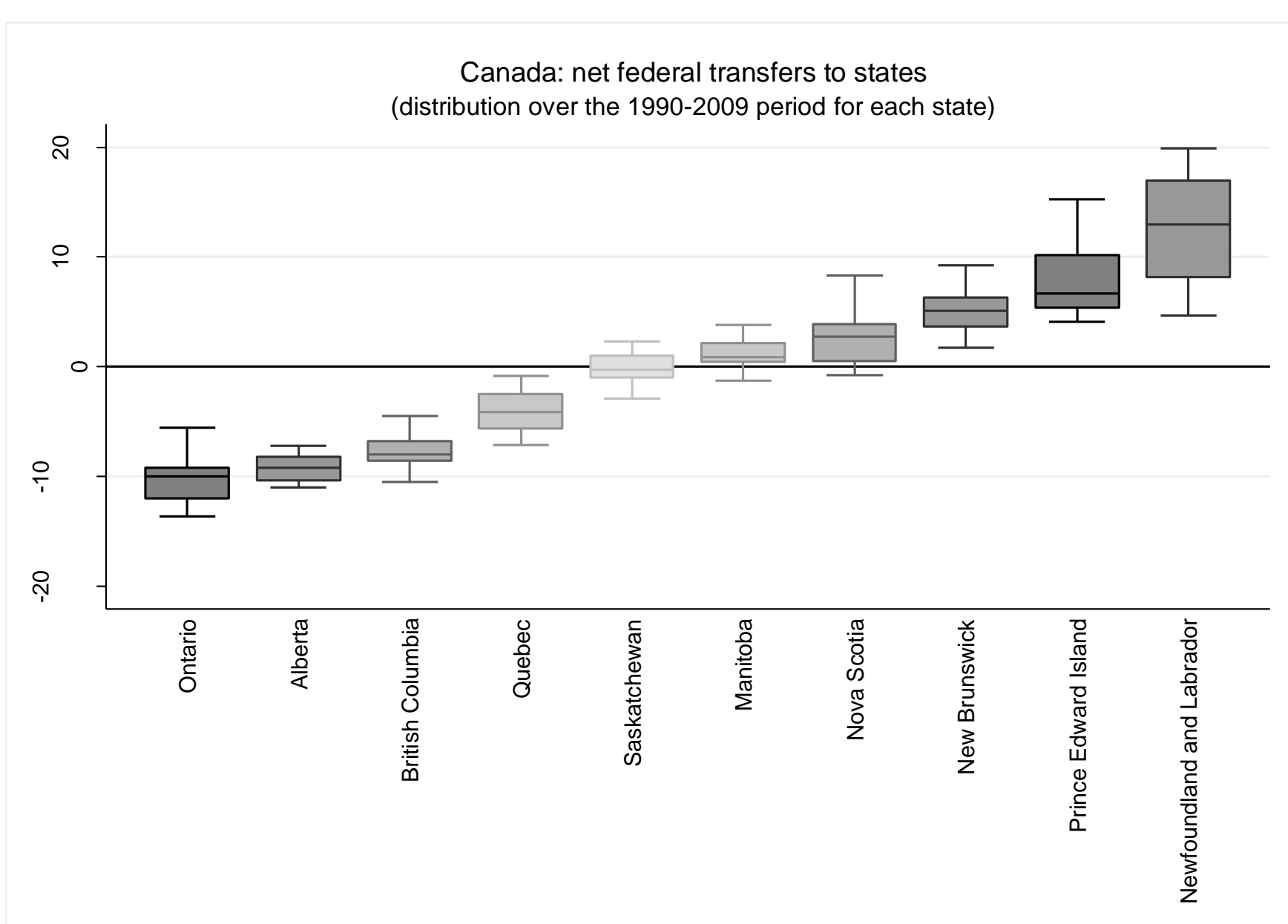

Note: The whiskers of the plot denote the minimum and maximum values of variables for each state within a country. The edges of the box denote 25 th and 75 th percentiles of the distribution. The line splitting the box denotes the median. 
Figure 6. Redistribution through Net Fiscal Transfers in Australia (1998-2010)

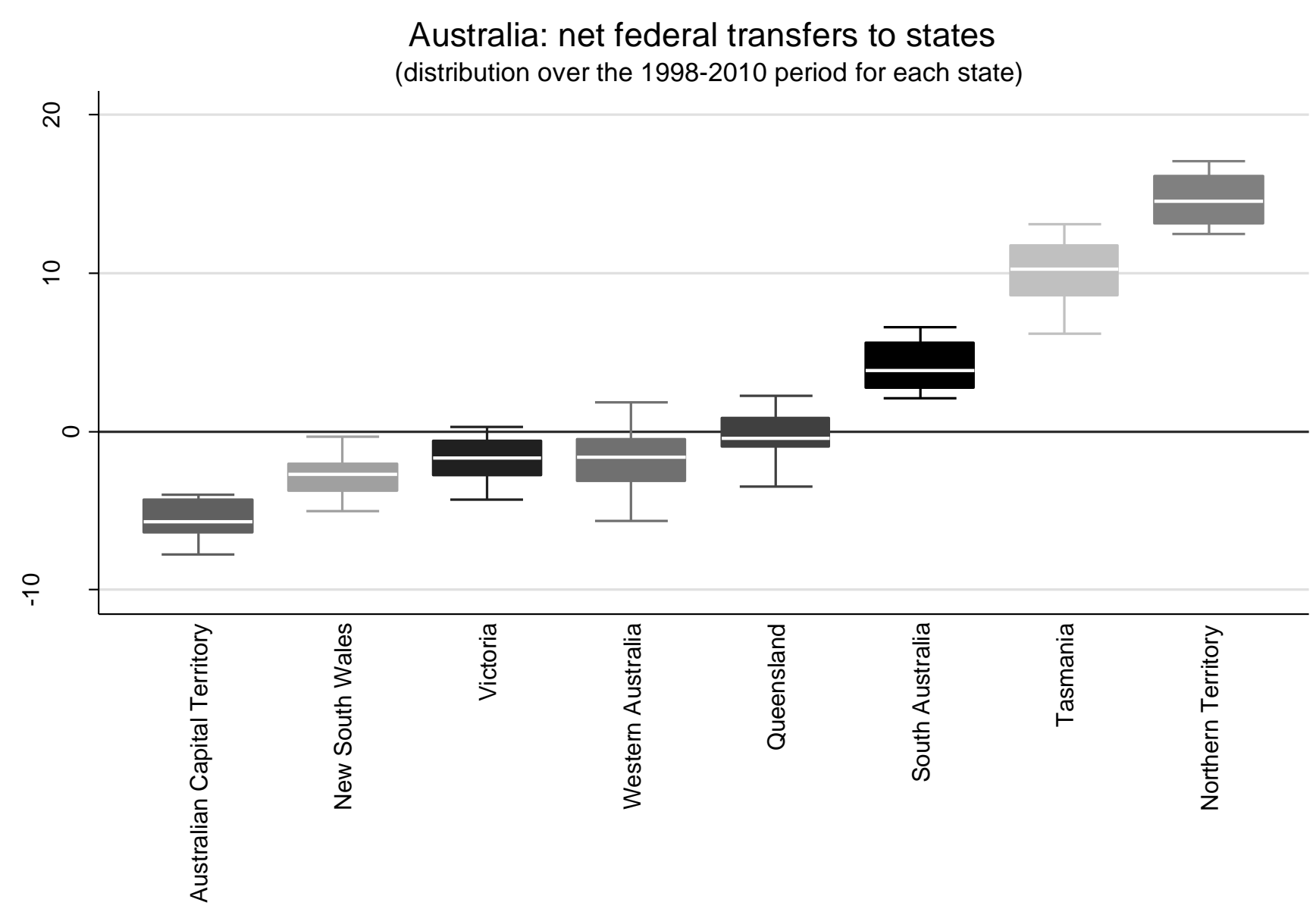

Note: The whiskers of the plot denote the minimum and maximum values of variables for each state within a country. The edges of the box denote 25 th and 75 th percentiles of the distribution. The line splitting the box denotes the median. 